\title{
Revisiting the Meaning of Leadership ${ }^{*}$
}

Joel M. Podolny $\quad$ Rakesh Khurana Marya Hill-Popper

Harvard University

October, 2004

Chapter to appear in Staw, B. M. \& Kramer, R. M. (Eds.), Research in Organizational Behavior, 26: 1-37.

\footnotetext{
${ }^{*}$ We wish to thank Rod Kramer, Mike Tushman, Barry Staw, and Jeff Pfeffer for helpful comments on an earlier version of this chapter.
} 


\begin{abstract}
During the past fifty years, organizational scholarship on leadership has shifted from a focus on the significance of leadership for meaning-making to the significance of leadership for economic performance. This shift has been problematic for two reasons. First, it has given rise to numerous conceptual difficulties that now plague the study of leadership. Second, there is now comparatively little attention to the question of how individuals find meaning in the economic sphere even though this question should arguably be one of the most important questions for organizational scholarship. This chapter discusses several reasons for the shift, arguing that one of the most important has been the lack of a clear definition and operationalization of meaningful economic activity. As a first step to redressing this shift, we offer a definition and operationalization of meaningful action, and we propose a typology of executive behaviors as a foundation for a systematic exploration of the meaning-making capacity of leaders. We conclude with a discussion of the relationship between the capacity of leaders to infuse meaning and the capacity of leaders to impact on performance.
\end{abstract}




\section{Revisiting the Meaning of Leadership}

\section{Introduction}

Through the 1960s, leading organizational theorists regarded the concept of leadership to be worthy of serious intellectual inquiry. Scholars such as Weber, Barnard, and Selznick believed that one could not fully understand what those in organizations believe or how they behave without reference to the presence (or absence) of organizational leaders. Leaders are the source of institutionalized values which, in turn, condition the actions of organizational members. Yet, for at least the past thirty years, the concept of leadership has been subject to criticism and marginalization by the dominant organizational paradigms and perspectives.

These criticisms have largely followed two related lines. One is that leadership, as a concept, is too loosely defined and is ultimately an amalgamation of behaviors and attributes that can be more readily defined and linked to performance when they are analytically decoupled (Pfeffer, 1977; Kerr and Jermier, 1978; Meindl, Ehrlich, and Dukerich, 1985; Hackman, 2002). While this particular criticism has been made forcefully by scholars who have sought to de-emphasize the leadership construct in the study of organizations, the criticism actually can be traced to advocates of the leadership construct in the sixties and seventies. Scholars such as Bennis (1959) and Stogdill (1974) bemoaned the lack of any agreement as to the defining elements of the leadership construct.

A second criticism, which has its origins in an influential study by Lieberson and O’Connor (1972), is that little variance in organizational performance can be systematically attributed to differences among individuals, and to the extent that 
differences in performance outcomes cannot be ascribed to individual differences, then leadership by definition cannot matter. Lieberson and O’Connor decomposed the overtime performance of 167 companies into the variance explained by macro-economic conditions, industry, company, and finally the organization's chief executive. Although the impact of the chief executive varied by industry (from little to none), external factors such as the type of industry and the organization's inherited characteristics account for far more variance than any "leadership" effects. ${ }^{1}$ Around the same time, Cohen and March (1974) conducted a detailed examination of forty-six college and university presidents and concluded that leadership is principally mythological. Likening the role of an organization's leader to the driver of a skidding car, they argue that there is little a leader can do to influence organizational outcomes, and "whether he is convicted of manslaughter or receives a medal for heroism [is] largely outside his control” (Cohen and March, 1974: 203). Numerous empirical studies have since supported Cohen and March's basic conjecture that factors outside the control of any single individual drive organizational performance (for a review and critical assessment of these studies, see Thomas, 1988, especially pp. 388-395, and also Wasserman, Bharat, and Nohria, 2001). The conclusion that individuals have an extremely limited capacity to impact organizational performance became a pillar of the dominant macro-organizational paradigms that emerged in the 1970s. Resource dependence scholars (Pfeffer and Salancik, 1978; Pfeffer, 1987) have contended that organizational action can be

\footnotetext{
${ }^{1}$ A few macro-level studies suggest that the impact of leadership on performance variation is greater than implied by the Lieberson and O’Connor study (e.g., House, Spangler, and Woycke, 1991), and there is evidence that the short-term price of a company's stock is influenced by the individual characteristics of the CEO (Flynn and Staw, 2004). Nonetheless, the evidence linking leadership attributes or behaviors to performance variation is thin, particularly in light of the popular belief in the importance of leadership to the performance of complex organizations.
} 
understood, not as an exercise of individual agency, but as a response to the demands of the external actors upon which the organization depends for resources and support. Sharing a similar theoretical premise, the new institutional perspective (Powell and Dimaggio, 1991) has maintained that external actors impose very specific expectations on what the organization should be doing. These external expectations can be so strong that they generate a template of strategies and structures that an organization mimics on the basis of presumed legitimacy (DiMaggio and Powell, 1983; Meyer and Rowan, 1977). Finally, organizational ecologists have argued that internal and external demands for accountability and reliability place tremendous constraints on the ability of individuals to direct organizational change so that the change improves the organization's fitness with its environment. Leaders can certainly make changes to the organization, but the combined effects of uncertainty and the constraints implied by the reliability and accountability demands mean that leadership has at most a tenuous impact on the success and failure of the organization (Hannan and Freeman, 1989; Carroll and Hannan, 2000). Granted there is a micro-organizational literature on leadership that can be traced back to Bales and Slater's studies (Bales, 1950; Bales and Slater, 1955) of emergent leadership behavior within small teams. In contemporary micro-organizational scholarship, the perspective of this literature is reflected in Hackman’s (2002) research and in Hambrick and Finkelstein's (1987) studies of top management teams, which do reveal the impact of leadership behavior on the performance of teams. Pfeffer and DavisBlake (1986), to take another example, found that NBA teams improve their performance after hiring a new, experienced coach. However, such research does not challenge the conclusions of Lieberson and O’Connor or Cohen and March, who are clearly focused on 
the significance of leadership for performance outcomes at a macro level, where the leader's success is thought to depend on his or her ability to impact the behavior of individuals with whom the leader does not have an ongoing personal relationship. Moreover, we believe that it is safe to assert that in the popular imagination, instances of great leadership are at least thought to occur in social contexts that are on a larger scale than a team or group.

In fact, far from contradicting these two major critiques of the leadership construct, the micro-organizational behavior literature reinforces these critiques by offering a view of leadership as an attribution process (Calder, 1977; Pfeffer, 1977). Rather than leadership being a determinant of superior organizational performance, the level of organizational performance determines the perception of leadership (Meindl, Ehrlich, and Dukerich, 1985). When individuals observe high-performance organizations, they assume that leadership must be present. In this sense, the belief in leadership is essentially one instantiation of the fundamental attribution error (Weber, Camerer, Rottenstreich, and Knez, 2001; Emrich, 1999).

Of these two major critiques of leadership, we believe that the second - that individuals can only have a limited impact on organizational performance - is a more serious challenge to the study of leadership than the first - that leadership is a poorly defined analytical construct. If the actions of individuals do not matter to organizational performance, then it necessarily follows that the actions of a leader cannot matter to organizational performance, regardless of whether a more adequate definition of leadership emerges from the field. 
Having briefly reviewed these two critiques, we would now like to draw attention to a fundamental assumption that is common to both: if leadership does not directly impact organizational performance, then leadership does not matter to organizational life. In effect, the relevance of leadership as an organizational phenomenon is circumscribed by its direct impact on performance. Critics of leadership research are not the only ones who seem to assume that the importance of leadership should be couched in terms of its direct impact on performance. Such an assumption certainly resonates with much work in neo-classical economics, in which a social phenomenon's importance is judged by its impact on economic outcomes. This assumption also resonates with what many see as the mission of business schools - to develop leaders who should ultimately judged on their ability to improve organizational performance (see Pfeffer and Fong, forthcoming). Even some of the strongest advocates of leadership as a construct take as a given that leadership is important because it is important to performance. Titles such as Leadership and Performance Beyond Expectations (Bass, 1985) or The Leadership Factor (Kotter, 1988) or The Transformational Leader: The Key to Global Competitiveness (Tichy and Devanna, 1986) exemplify attempts to make explicit links between leadership and performance. While there has been some work that moves beyond the impact of leadership on performance, it remains largely the case that a concern with leadership is inseparable from a concern with performance.

The central premise of this chapter is that the study of leadership within organizational theory went awry as this assumption seeped into the disciplinary concern with leadership. If one revisits the work of scholars such as Weber $(1946,1978)$, Barnard (1968), and Selznick (1984), it becomes clear that they were not concerned with 
leadership because of the concept's ability to explain economic performance. Instead, leadership was deemed important because of its capacity to infuse purpose and meaning into the lives of individuals. Although the issue of economic performance is not irrelevant to their examination of leadership, it remains of secondary importance. Accordingly, if we are to judge the importance of leadership to organizational life, we need to assess the importance of leadership in terms of its ability to infuse purpose and meaning into the organizational experience.

However, this observation begs several questions: (a) If the concept of leadership was initially couched in terms of its significance for meaning-making, why and when did the concept become decoupled from meaning-making? (b) How does one assess the extent to which a leader infuses action with meaning? (c) What is the connection between meaning-making capacity and economic performance? These questions are the central focus of this chapter. Before we address them, however, a review of the literature pertaining to the meaning-making capacity of leaders is in order.

\section{Leadership as Meaning-Making}

The preoccupation of classic social theorists with the meaning-making capacity of leaders can be traced to an even more fundamental concern with the uneasy relationship between the capitalist mode of exchange on the one hand, and the state of modern lived realities on the other. Early $19^{\text {th }}$ century scholars, while embracing modernity, also recognized its implications for the human spirit and creativity. They were troubled by the emerging tensions between traditional meaning-making institutions, such as religion, family, and community, and modern institutions, such as the bureaucratic organization 
and the market economy. Tonnies (1957) dichotomized the life of community (Gemeinschaft) and the transactional life of society (Gesselschaft); Durkheim (1947a) described the transition from mechanical to organic solidarity not as a smooth, gradual process, but a discontinuous and potentially anomic process that disconnected individuals from the traditional institutions that infused value into their lives. Finally, Weber (1946, 1978) believed modernization implied an ever-increasing rationalization of all aspects of life, as the dry logic of bureaucratic institutions steadily replaced the meaning systems derived from the wonder and enchantment of religion, respect for tradition, or the awe of charisma (see especially Weber, 1946, pp. 137-143, 155; Weber, 1978, pp.1121-1157). According to Weber, although it was true that the "ghost of dead religious beliefs" continued to animate industrial capitalism in the form of social habits like delayed gratification, thrift, and a sense of calling, modern society was rapidly constructing an "iron cage" of impersonal rationalism which would suffocate the human spirit and deprive human existence of meaning (Weber, 1992: 181-182).

While the concern with the loss of meaning was common across these theorists, Weber stands out from the others in looking to "extraordinary," charismatic individuals as a counter to the inevitable decline in meaning. Durkheim (1947a), for example, looked to professional associations to provide individuals with a shared and common meaning; the problem, of course, was that there was little evidence that these professional associations could equal the meaning-making capacity of the more traditional institutions, such as family or religion. In contrast, Weber (1946) could point to extraordinary individuals who were able to bring an alignment between the actions that individuals undertook and the meaning that they sought (see pp. 245-252 on charismatic authority 
and pp. 79-80 on political leadership). For example, in his discussion of the emergence of ascetic Protestantism, Weber details how John Calvin led his parishioners to adopt new attitudes in which worldly activity took on a religious value; manual labor and the pursuit of profit through business enterprise became infused with meaning, and, as a byproduct, traditional Christian suspicions toward wealth were reconciled with the requirements of capitalism (Weber, 1992).

Almost by definition, the phenomenon of charismatic leadership implies that followers come to perceive their actions as coupled to valued aspects of their lives. As Shils would later comment (1982: 122):

\footnotetext{
The charismatic quality of an individual as perceived by others, or himself, lies in what is thought to be his connection with (including possession by or embodiment of) some very central [italics added] feature of man's existence and the cosmos in which he lives. The centrality coupled with intensity, makes it extraordinary. The centrality is constituted by its formative power in initiating, creating, governing, transforming, maintaining, or destroying what is vital in man's life.
}

The close relationship between charismatic leadership and meaning is rooted in the fact that both are concerned with the contribution to and reproduction of a social order that is inherently valued by the individual.

For Weber, charismatic leadership is essentially antithetical to organization and therefore an inevitably transitional phenomenon (1946: 248-252). In order for the followers of a charismatic leader to feel that their actions have impact, the leader must organize those followers, and if this organization is to be effective, the leader will need to put in place structures and routines that necessarily imply the routinization of action. The meaning imbued in the original charismatic movement becomes embedded in the structures and practices of a rational, bureaucratic organization. Over time, Weber 
argued, routinization initiates a process that neutralizes and then finally obliterates the original values that led to the development of the organization in the first place (Weber, 1978: 1121-1157).

Organizational scholars of the early to mid twentieth century, such as Barnard (1968), Roethlisberger (Roethlisberger and Dixon, 1939), Mayo (1960), and Homans (1950), questioned the inherent incompatibility between the development of organization and the infusion of values and purpose. The primary reason that these scholars did not see as strong a tension is that they did not see bureaucracy as having unquestionably superior organizational properties. They argued that the survival of an organization depends on the willingness and ability of its members to adjust in a coordinated fashion to any environmental change that threatens the existence of the organization. This desire and capacity to respond in a coordinated fashion cannot be induced by bureaucratic structures or strong economic incentives. Rather, it depends on the extent to which those in the organization internalize a common purpose and perceive the connection between their actions and the organization's ability to fulfill this common purpose.

In The Functions of the Executive, Barnard (1968) asserts that it is the role of the leader to create a common awareness of and belief in the organization's purpose, without which there would be insufficient effort to ensure the organization's survival. Barnard denied the adequacy of economic incentives for fostering a level of effort sufficient to ensure the long-term survival of the organization. "It seems to...be definitely a general fact that even in purely commercial organizations material incentives are so weak as to be almost negligible except when reinforced by other incentives” (1968: 144). For Barnard, the survival of the organization rested on the executive's capability in establishing a 
common purpose as a basis for cooperation and creating a system for communicating that purpose.

Barnard thus offers a view of organization in which there is congruence between the creation of meaning and purpose, on the one hand, and efficient and effective organization, on the other. In establishing this congruence, Barnard seems to collapse the concepts of purpose and meaning, assuming that the former is tantamount to the latter. Such an assumption represents a departure from Weber. As just noted, for Weber, meaningful action is necessarily action that supports "vital” aspects of the individual's life. Such vitality need not necessarily be an aspect of organizational purpose; purpose can be experienced as an external constraint or force compelling the individual to make choices that the individual regards as inconsistent with his or her identity. The difference is perhaps best reflected in a vignette that Barnard offers about a telephone operator's adherence to the moral code of her organization (1968 [1938]: 269):

I recall a telephone operator on duty at a lonely place from which she could see in the distance the house in which her mother lay bedridden. Her life was spent in taking care of her mother and in maintaining that home for her. To do so, she chose employment in that particular position, against other inclinations. Yet she stayed at her switchboard while she watched the house burn down....She showed extraordinary "moral courage"...in conforming to a code of her organization - the moral necessity of uninterrupted service.

The operator certainly feels the purpose of the organization in choosing to remain at her station, but it is hard to believe that the activity carries more meaning than saving the life of the loved one whose care provided the initial impetus for taking the job. As we shall discuss in more detail later in this chapter, one unfortunate consequence of confounding meaningful action and purpose-imbued action is that it leads scholars to assume that strong culture organizations are necessarily infused with meaning. As a number of 
ethnographic studies have shown, strong culture organizations can often be ones in which individuals have the greatest difficulty reconciling action with their own identity and, accordingly, find themselves engaging in action that they do not regard as meaningful (e.g., Kunda, 1992; Van Maanen, 1991; Martin, 1992; Weeks, 2004).

Selznick's work on organization and leadership echoes Barnard's, though Selznick’s conception of meaning is closer to Weber's. Like Barnard, Selznick conceptualizes an organization as a cooperative system. Selznick describes the dual nature of organizations as both economic entities, with the goal of achieving technical efficiency vis-à-vis the process of production, and as "adaptive social structures” whose fundamental goal is organizational survival (Selznick, 1984). For Selznick, an organization is, at a minimum, “a lean, no-nonsense system of consciously co-ordinated activities. It refers to an expendable tool, a rational instrument engineered to do a job” (1984: 5). However, an organization becomes an institution when it is "infuse[d] with values beyond the technical requirements of the task at hand" (Selznick, 1984: 17). It is the role of leadership to turn an organization into an institution, by infusing the organization with values and creating a distinct organizational identity and sense of purpose that is in fact internalized by organizational members as meaningful.

Selznick identifies four key activities of leaders: definition of institutional mission and role; institutional embodiment of purpose; defense of institutional integrity; and the ordering of institutional conflict (1984: 62-64). In each of these activities, balancing internal and external constraints is central. ${ }^{2}$ To the degree that the leader successfully

\footnotetext{
${ }^{2}$ The emphasis on external constraint is one way in which Selznick departs from Barnard. In his discussion of organizational mission, for example, Selznick describes the role of a university president: "A university president may have to accept some unwelcome aspects of alumni influence; he would be a poor leader if he did so without knowing whether his dependency was truly part of the institution's character" (1984: 70).
} 
executes the four key activities, the subordinate's participation in organizational life gives rise to a distinctive set of valued commitments. The subordinate comes to regard his or her actions as meaningful in so far as those actions further the organizational purpose.

To summarize, Weber, Barnard, and Selznick were all concerned with leadership as a phenomenon because of the importance of leaders for creating meaning. There are, however, important differences between the three scholars. For Weber, leadership is almost necessarily a non-organizational phenomenon, since the rationalization implicit in organization undercuts meaning. For Barnard and Selznick, leadership is an organizational phenomenon, but Barnard does not distinguish between adherence to an organization's purpose and an alignment of purpose with the vital aspects of an individual's life. Later in this chapter, we shall return to some of these scholars' ideas, especially when we seek to develop more definitive conceptions of leadership and meaning for research going forward. For now, we simply wish to establish that existence of a "classic" tradition in which leadership is significant primarily because of its importance for meaning creation.

\section{Decoupling the Joint Focus on Leadership and Meaning}

Having underscored that leading organizational scholars identified leadership with meaning-making and having noted these and other scholars' concern with loss of meaning in modern organizations, we can now return to answering the first of the three questions posed in the introduction: if the concept of leadership was initially couched in terms of its significance for meaning-making, why and when did the concept become decoupled from meaning-making? Our answer is necessarily a speculative exercise in 
intellectual history. However, we believe that the reason for the departure can be traced to four particular developments in post-World War II organizational theory.

If, as social theorists since Weber have argued, a central tendency of modernity has been the extraction of meaning from action, and if this tendency has become manifest across organizations, then it should not be surprising that scholars should no longer see meaning-making as central to organizational life. The fact that meaningful action is less present in the typical organization does not necessarily imply that it is any less important to understand how meaning in organizations is created. However, it is easy to understand how interest in a phenomenon can wane when that phenomenon is not observed.

A second reason for the declining interest in the meaning-making capacity of leaders is that social processes involving meaning-making are difficult to quantify and operationalize. Since the early 1970s, organizational theory has increasingly concerned itself with phenomena that lend themselves to more straightforward quantification and statistical analysis (Sørensen, 1998). Against this backdrop, a phenomenon such as meaning-making seems less useful as an analytical construct than the more easily quantified indicators of performance. Put more crudely, return on investment (ROI) makes for a more tractable dependent variable than meaning.

A third and related reason for why organizational scholarship emphasizes the connection of leadership to economic performance over other more subjective variables such as meaning is the shift in the location of organizational research in universities. Today, most organizational research takes place in business schools (Pfeffer, 1997: 13; Walsh, Weber, and Margolis, 2003: 871). Since performance is arguably the central concern for business organizations in general, the desire to elucidate the causes of 
performance is very strong in the marketplace of ideas. Walsh, Weber, and Margolis (2003), for example, found that organizational research over the past decade has increasingly focused on economic performance (or some variant of it) as a dependent variable. In explaining this trend, we note that Pfeffer and Fong's (forthcoming) comment about business school students applies equally well to faculty: business school faculty are social beings - they are subject to social influence, to learning from their environment about what is important, and to the frames provided by their organization (see also Salancik and Pfeffer, 1978 and Pfeffer 1997: 14-16). Faculties have responded to messages about the importance of performance as a dependent variable and, as a result, their research emphasizes exactly what one might expect.

Changes in institutional theory represent a fourth cause of decoupling a focus on leadership from a focus on meaning. Of all the schools of organizational thought, the new institutional theory of organizations comes closest to being a perspective that puts meaning at the center of its conceptual framework. Like Selznick’s early institutionalism, the new institutionalism focused attention on the link between organizational processes and how they came to be understood by organizational actors. However, perhaps as part of the general backlash against Parsonsian functionalism in the 1960s, new institutional theory supplanted the idea of meaning-making with the more cynical notion of myth creation (Meyer and Rowan, 1977). Those at the top of the organization did not facilitate an organization’s survival by infusing it with a meaning that transcended short-term economic performance. Rather, they improved the prospects of long-term survival by engaging in symbolic behavior that buffered the organizational core. Whereas Selznick saw the displacement of an organization's formal goals by those 
which are more general and directed toward organizational survival as a natural part of institutionalization, new institutional theorists interpret this action as if it were an indication that an organization has sold out its goals in order to survive and/or grow.

A few examples of the way new institutional scholarship looks behind the "myths" of organizations might serve to clarify our argument. In his study of a California community college, Clark (1960a, 1960b) showed that although most students saw the community college as a continuing education preparing them for transferring to a fouryear college, because of the students' marginal academic abilities much of the course work was in fact a repeat of the last two years of high school. ${ }^{3}$ Neither the teachers nor the students overtly acknowledged that the community college course work was an attempt to supplement and draw attention away from failing high schools. In fact, much of the remedial nature of the community college was guaranteed and supported by a web of individuals and organizations in the community, including the teachers from the failing high schools who also worked at the community college. Clark's account suggests that community college merely served to shield students from the reality that their high schools had failed to adequately prepare them for college.

More recently, Dobbin and colleagues' research on equal opportunity and diversity programs suggests that these programs are decoupled from core organizational goals and routines; they serve a largely symbolic, not substantive, role. Studying the creation of equal opportunity offices and programs following the Civil Rights Act of 1964, Dobbin and Sutton (1998) find that adoption was driven not by what organizational leaders regarded as meaningful but rather by the activity of management specialists in response to new and highly ambiguous federal legislation. Once in place, the programs

\footnotetext{
${ }^{3}$ See also Brint and Karabel, 1991 for a discussion of the transformation of community colleges.
} 
remained decoupled, symbolic entities that allow the organizational core to continue human resource management routines in an unchanged fashion. The shift in the rhetorics used to justify the programs is one sign of the symbolic role they played (Dobbin and Sutton, 1998; Kelly and Dobbin, 1998). Initially couched in terms of legal compliance, the programs were then justified based on efficiency rationales (Dobbin and Sutton, 1998). In a second rhetorical shift, antidiscrimination programs were reframed as diversity management programs (Kelly and Dobbin, 1998). Finally, examining the impact of diversity programs in changing the racial composition of management ranks, Dobbin and colleagues find that the programs' effectiveness is significantly greater among firms subject to federal affirmative action law, as compared to firms subject only to the more general equal opportunity law (Kalev, Dobbin, and Kelly, 2004). Absent regulatory force, the programs seem to have little impact on core organizational practices. A similar interpretation is given to organizational attempts to provide members with a sense of broader purpose or to explicitly articulate organizational values. Khurana (2002), for example, sees this as part of a broader trend toward elevating business to an activity that transcends the profane task of money-making and infusing it with a moral dimension. Corporations' significance for their members, Khurana argues, "has become quasi-religious, as suggested by the importation of terms such as mission and values into the contemporary corporate lexicon” (Khurana, 2002: 71). The implication is that the changes are more symbolic than real.

At the same time that some institutional theorists were reinterpreting meaningmaking as myth creation, other institutional theorists were arguing that the meaningless pursuit of economic efficiency in the $20^{\text {th }}$ century had actually emerged as a culturally 
meaningful social end. Whereas Weber's Calvinists regarded the ascetic accumulation of capital as meaningful because it provided information as to whether they were predestined for heaven, those living in the $20^{\text {th }}$ century came to regard efficient economic organization as a valued end regardless of the output or purpose of the organization. Efficiency and rationalism are thus seen as part of a specific cultural system of measuring value (Smelser, 1995; Bell, 1976).

Roy (1997) and Marchand (1998), for example, argue that large corporations came to be accepted as legitimate, not because they performed better than smaller firms, but because scale economies were rationalized as central to operating efficiency, and efficiency was simply a taken-for-granted social good. If the pursuit of efficiency is necessarily meaningful, then Selznick’s (1984) distinction between routine administrative activities and the institutional function of leadership necessarily breaks down, because what is profitable becomes defined as vital and central to an individual's life. A focus on leadership and a focus on economic performance become inseparable.

As we see it, the problem with both trends in institutional theory is that they water down any distinction between meaningful and meaningless activity and, as a consequence, make “meaning creation” a meaningless notion. Meyer and Rowan (1977) provide no basis upon which to distinguish a meaningful purpose from a meaningless myth. Similarly, if practically any economic action can be rationalized as being in the pursuit of economic efficiency, and if economic efficiency is a valued end in itself, then any action can be understood as meaningful. Institutional theory assumes that the ritualistic and symbolic activity at, for example, a Mary Kay annual meeting is simply mythic activity designed to fool the legions of saleswomen that what they are doing is 
meaningful when in fact it is not; or, institutional theory assumes that the pervasiveness of the market culture ensures that an investment banker can find as much meaning in her work as a priest. ${ }^{4}$ Both assumptions give rise to a vacuous notion of meaning. In order for individuals to find meaning, the possibility of meaningless activity must be present to them.

Of course, we cannot redress these turns in institutional theory unless we develop an operationalization of meaningful activity that does allow one to distinguish what is meaningful from what is not. That is, to the extent that one cannot assess the creation of meaning, then one is essentially replacing the difficult-to-operationalize construct of leadership with the difficult-to-operationalize construct of meaning-making. This leads us to the second question posed at the outset of this chapter: how does one assess the extent to which a leader infuses action with meaning?

To answer this second question, we need to realize three objectives. We need to offer a definition of meaningful action. We then need to provide an empirical methodology for ascertaining whether action in a particular context can be interpreted in a way that conforms to the conception of meaning. Finally, we need to specify the scope of leadership behaviors that are of at least potential relevance to the infusion of meaning.

\section{Defining Meaningful Action in Organizations}

Our earlier review of Weber, Barnard, and Selznick provides some indication as to how meaning might be defined; their work suggests that meaningful action is action that is internalized as having significance beyond mere technical efficiency - as being

\footnotetext{
${ }^{4}$ While not firmly within the institutional theory paradigm, Pfeffer's (1981) view of management as symbolic action shares many similarities with the Meyer and Rowan (1977) interpretation of management behavior as myth-making.
} 
connected to vital aspects of one's life. However, unless the term "vital" is unpacked, it is not clear that the term has any greater analytical specificity than meaning.

We contend that there are two ways in which the vital aspects of one's life and hence meaning can be conceptualized. Each can be considered a component of a full conception of meaningful action in organizations. One component draws on German social theory and emphasizes that meaning is created when action is directed toward a broader ideal; the other component draws on French social theory and emphasizes the importance of relationships to meaning. Let us consider each component in turn.

The German conception of meaning originates with Hegel's (1952) concept of human action as oriented toward a Geist or ideal. Weber (1964) uses the term "substantive rationality" (wertrational) to describe this orientation and contrasts it with "formal rationality" (zweckrational). ${ }^{5}$ Whereas action guided by formal rationality involves simple means-end calculations, action guided by substantive rationality implies that action originates from "a conscious belief in the absolute value of some ethical, aesthetic, religious, or other form of behavior, entirely for its own sake and independently of any prospects of external success” (Weber, 1964: 115). In modern society, these aspects of life may be in tension with one other. The tension between substantive and formal rationality is most apparent when aspects of society that are considered sacred are profaned by equating their purported value with the price these products can command in the course of commercial exchange. Zelizer, for example, has described the tensions

\footnotetext{
${ }^{5}$ Weber defined formal rationality as an orientation toward action in which "the end, the means, and the secondary results are all rationally taken into account and weighted” (Weber, 1964: 117). The conception is closest to economic notions of action: independent agents consciously evaluating choices and making decisions based on optimizing the costs and benefits between a series of alternatives. Examples can be found in rational choice theories in sociology, economics and political science (e.g., Coleman, 1990; Brinton and Nee, 1998; see also Swedberg, 1998 for an extended discussion of Weber's original concepts of formal and substantive rationality).
} 
between the market for child labor and the substantive values of childhood as a sacred period in human life, as well as between the market for life insurance and the normative resistance against such a product, resistance rooted in the notion of human life as sacrosanct and priceless (Zelizer, 1985; Zelizer, 1979). More recently, these tensions can be identified in efforts to establish commercial blood banks, the debate over public funding for stem cell research, and prohibitions against the sale of human organs (e.g., Healy, 2004).

The second component of meaningful action can be traced at least to Rousseau, who recognized the importance of social interconnectedness and communal relations in infusing our lived experience with meaning. In The Social Contract and Discourses, Rousseau writes (1993: 142-143):

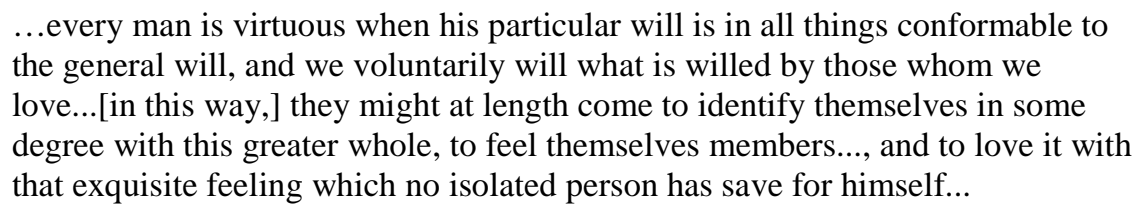

Rousseau, in effect, contends that the quest for meaning is attained through social communion, a process in which an individual realizes herself through achieving solidarity in transparent relationships with others. Durkheim has a similar understanding of the individual as finding meaning through his or her connections to others, though Durkheim (1947b) replaces Rousseau's conception of the "general will” with his own conception of the conscience collective. Prior to the secularization of modern life, religion played this meaning-making role by providing a set of "beliefs and practices which unite into a single moral community... all those who adhere to them” (Durkheim, 1947b: 62). Absent collective life, the individual cannot distinguish between ends which are healthy and 
those which lead to anxiety and anomie. This standpoint is identical to that set out in Durkheim's discussions of the problem of modernity for human existence in both Suicide (1951) and The Division of Labour (1947a). In modern society, Durkheim saw organizational life replacing the traditional meaning-making role of religion. The rules of one's occupational role occupy the same imperative that religion once did. "They force the individual to act in view of ends which are not strictly his own, to make concessions, to consent to compromises, to take into account interests higher than his own.

Consequently, even where society relies most completely upon the division of labor, it does not become a jumble of juxtaposed atoms, between which it can establish only external transient contacts. Rather the members are united by ties which extend deeper and far beyond the short moments during which the exchange is made. Each of the functions that they exercise is, in a fixed way, dependent upon others, and with them forms a solidary system.” (Durkheim, 1947a: 228). ${ }^{6}$ As was the case for Rousseau, Durkheim proposes that for action to be meaningful, the enactment of values or purpose needs to occur in the context of community.

Though Selznick does not draw a direct connection between his conception of meaning and these two traditions, the emphases of both are implicit in the activities that Selznick associates with the institutional function of leadership. In discussing the definition of institutional mission and role, Selznick observes (1984: 65):

\footnotetext{
The institutional leader in his role as goal-setter must confront all of the classic questions that have plagued the study of human aspiration. When is an aim, such as "happiness," specific enough to be meaningful? What is the right role of reason, and of opportunism, in the choice of ends? How may immediate practical goals be joined to ultimate values?
}

\footnotetext{
${ }^{6}$ Later in his life, however, Durkheim expressed greater skepticism about the role of professional associations in providing this meaning, calling instead for a secular religion in the form of nationalism (Durkheim, 1947b).
} 
The connection to the German conception of meaning should be apparent in the above quote. At the same time, the other three leadership functions - the institutional embodiment of purpose, the defense of institutional integrity, and the ordering of institutional conflict - represent important aspects of transforming the collection of individuals in the organization into a community that finds meaning in their continuing pursuit of common objectives. Selznick writes (1984: 16):

To the extent that they are natural communities, organizations have a history; and this history is compounded of discernible and repetitive modes of responding to internal and external pressures. As these responses crystallize into definitive patterns, a social structure emerges. The more fully developed its social structure, the more will the organization become valued for itself, not as a tool but as an institutional fulfillment of group integrity and aspiration.

In linking the fulfillment of group integrity and aspiration to the development of community and social structure, Selznick evokes the French conception of meaning.

To summarize, our definition of meaningful action within organization has two components. An action is meaningful when its undertaking (1) supports some ultimate end that the individual personally values and (2) affirms the individual's connection to the community of which he or she is a part. ${ }^{7}$

\section{Operationalizing Meaningful Action in Organizations}

While we can draw on the German and French traditions for a two-component definition of meaning, in order to provide a concept of leadership as meaning-making that is analytically tractable, we must move beyond a definition and consider the issue of

\footnotetext{
${ }^{7}$ This definition allows us to distinguish meaningful from meaningless action by specifying the form that meaningful action will take. The content of what is found meaningful - the valued end toward which action is directed - can vary considerably across individuals.
} 
operationalization. We noted earlier our belief that scholarship on leadership moved away from a concern with meaning creation at least in part because meaningful action is so difficult to operationalize.

One could even argue that a concern with meaning defies operationalization, at least in so far as the term operationalization implies the construction of variables that are amenable to conventional quantitative analysis. If one can only understand the meaning of action through the empathetic comprehension of intentionality and context (what Weber (1964) called verstehen), then any distillation of a social context into reified variables potentially interferes with that understanding. For example, given an objective of assessing the meaning of action, we would have to question the utility of any survey methodology in which participants are asked such questions as, "Do you find your work meaningful?” or “Does your work make you happy?” The answers to such questions hardly seem to lend themselves to elucidating the meaning that Weber (1992) identified in The Protestant Ethic or Selznick (1952) uncovered in The Organizational Weapon, his study of the Boshevik party’s transformation from a voluntary organization to a "combat party."

\section{Language as a lens}

We propose a methodology that does not rely on survey responses, but instead relies on the language that individuals employ for talking about work as an unobtrusive indicator of the meaning they derive from their experiences. Rather than focusing on what individuals say about work (e.g., “I am happy”), we draw on recent developments within the field of linguistics and contend that it makes more sense to focus on how 
individuals talk about their work. For example, consider the following two sentences that a worker might use to describe his experience of work:

(1) We feel considerable pressure to perform when we are at work.

(2) There is a lot of performance pressure for those who work here.

In terms of content, the two sentences express essentially identical content. Both reflect a sentiment of experienced performance pressure. However, there are differences in the pronoun references ("we” versus "those...here”). In comparison to the second sentence, the first sentence implies less distancing of the self from the others at work and less distancing of the self from the work experience. In the first sentence, the performance pressure is temporally bounded ("when we are at work"), whereas the second sentence does not imply a similar temporal bounding. More subtle, in the first sentence, there is a sense that the "we" exists before and after work; so while the performance pressure of work is temporally bounded, "we" is not. Finally, in the second sentence, performance pressure has become reified as a thing in the environment rather than a feeling that is "owned" by the participants.

While neither sentence allows us to conclusively assess the extent to which the experience of work is meaningful in the sense of being connected to ultimate ideals, the first sentence clearly reflects greater meaning in the sense that the individual is connected to others around him. Moreover, the fact that "performance pressure" has been reified in the second sentence is at least a clue that the pressure reflected in the second sentence is less likely to be connected to the self and therefore almost necessarily what the self values. So, while one cannot conclusively make an inference about which sentence is more indicative that the worker finds his work to be meaningful, we would assert that sentence (1) is at least suggestive of greater meaning than sentence (2), and to the extent 
that sentence (1) is situated among more sentences that were similarly suggestive of the meaningfulness of work, we could in fact draw stronger inferences.

We believe this focus on grammar as an indicator of meaning can be justified on two grounds. First, there is research on the relationship between language and health outcomes that has found that the content of what people say and write yields few significant relationships to a variety of mental and physical health indicators, but that how people speak and write is associated with the health outcomes of interest (e.g., Pennebaker, 2002; Cambell and Pennebaker, 2003; Pennebaker and Graybeal, 2001). Psychologists, in particular, have turned their attention to what linguists call "particles" linking words such as articles, pronouns, prepositions, conjunctions, and auxiliary verbs. Pennebaker (2002), for example, finds that disproportionate use of the first person singular pronoun "I" is associated with depression, whereas references to other people (e.g., by use of the first person plural “we”) are disproportionately absent among depressed individuals. In related studies, Campbell and Pennebaker (2003) find that flexibility in using pronouns (e.g., diversity in use of pronouns across a body of written narratives) is associated with positive health outcomes. Summarizing the results of this work, the authors conclude: "Changes in writing styles were consistently associated with better health, whereas similarity in the content of writing was unrelated to health outcome. Closer analyses of the factors that defined writing styles indicated that particles, and in particular pronouns, predicted the health changes. Individuals who altered their individual and social perspectives from day to day were the participants most likely to benefit from the disclosure exercise” (Campbell and Pennebaker, 2003: 64). Obviously mental health and meaning are not identical constructs, and because this 
psychological work does not focus on how an individual's conception of self is (or is not) grounded in the experience of work, there are limits as to how much one can directly infer from this research to date. At the same time, this research is important in so far as it provides some justification for making inferences about meaning based on how individuals express themselves rather than on simple extrapolation from the content of what is expressed.

Further justification for a focus on how an individual communicates rather than what he or she communicates comes from the field of linguistics itself. Scholars such as Halliday (1994; Halliday and Matthiessen, 1999) and Silverstein (2003) have increasingly turned their attention to understanding the connection between the language with which the individual describes his or her reality and the way in which that reality is experienced. Matthiessen and Halliday (1997) express the premise guiding the focus on language: “Language does not passively 'reflect' or 'construct' some pre-existing reality. Language constructs reality; or rather, we, as human beings, construct reality in language. We do this through the metafunctional interplay of action and reflection: language both enacts interpersonal relationships and construes human experience.” The link between language and experience is not automatic. In construing experience through language we have a range of lexical and grammatical options on which we can draw, and the choice of one particular means of expressing our experience over another is the process by which we construe our reality in a particular way.

Further below, we shall consider some of the systematic grammatical rules uncovered by linguists that can be useful in making inferences about the extent to which an individual finds meaning in his or her actions. However, before doing so, we believe 
that a few examples can help to make the case for the focus on language as a lens to uncovering meaning. For the purpose of this illustration, we draw on a few interviews from Studs Terkel's Working (1972), a book in which individuals from a broad spectrum of occupations provide the author with their personal reflections on their work. Terkel opens the book with an interview of a steel worker who reflects on the difficulty of finding meaning in manual labor (1972: 1-2):

\begin{abstract}
You can't take pride any more. You remember when a guy could point to a house he built, how many logs he stacked. He built it and he was proud of it. I don't really think that I could be proud if a contractor built a home for me. I would be tempted to get in there and kick the carpenter in the ass (laughs), and take the saw away from him. 'Cause I would have to be part of it, you know.

It's hard to take pride in a bridge you're never gonna cross in a door you're never going to open. You're mass producing things, and you never see the end result. (Muses) I worked for a trucker one time. And I got tiny satisfaction when I loaded the truck. At least, I could see the truck depart loaded. In a steel mill, forget it. You don't see where nothing goes.
\end{abstract}

It is interesting to attend to the shift in pronouns. While the steel worker uses "I" when talking about activities that did or would make him proud and provide him with satisfaction ("I would be tempted to kick the carpenter...I got tiny satisfaction when I loaded the truck"), he shifts to "you” when talking about what manual labor in a steel mill is like. ("You can't take pride any more....It's hard to take pride in a bridge you're never gonna cross...In a steel mill, forget it. You don’t see where nothing goes.”) Implicitly, there is less distance between the self and the activity when the activity is more meaningful. Reading through the full interview, moreover, it is noteworthy that the worker almost never refers to "we" when discussing work. There is no natural community of which he feels a part. In short, how the steel worker talks about work reveals as much about the distance of his self from his work and from others at work as does the content of what he says. 
Terkel also interviews a prostitute, who reveals another type of linguistic distancing of self from work (1972: 96):

You're expected to be well dressed, well made up, appear glad to see the man....There's a given way of dressing in that league - that's to dress well but not ostentatiously. You have to pass doormen, cabdrivers. You have to look as if you belong in those buildings on Park Avenue or Central Park West. You're expected not to look cheap, not to look hard....

Preparations are very elaborate. It has to do with beauty parlors and shopping for clothes and taking long baths and spending money on preserving the kind of front that gives you a respectable address....

As with the steel worker, the pronouns are an important part of the story. Though we have not included some references to "I" for the sake of space, it is clear that the prostitute describes much of her work in terms of what "you” need to do. However, beyond the pronoun references, there are two other features of the speech that stand out. In the first paragraph, most of the agency resides with the expectations of others. That is, "you have to" act a certain way because of what others expect. Perhaps even more notable is the reliance on gerund constructions ("shopping”, "taking”, "spending”) as a way of objectifying her actions; the gerund constructions allow for the self to be completely removed from the speech.

By way of comparison, consider the following transcript of an interview with a jockey (Terkel, 1972: 472-473):

I have been having a little problem of weight the last three weeks. I've been retaining water which I usually do not do....I've learned to reduce from other riders who've been doing it some twenty-some years. They could lose seven pounds in three hours.

Riding is very hazardous. We spend an average of two months out of work from injuries we sustain during the year. We suffer more death than probably any other sport...

The most common accident is what we call clippin' another horse's heels. Your horse trips with the other horse's heels, and he'll automatically go down. What helps us is that the horse is moving at such momentum, he falls so quick, that we just sail out into the air. 
In this interview, there is almost a continual alternation between "I,” "they," "you,” and “we.” There are in fact no clear boundaries that are being drawn between the self and others. There is also little objectification of action through the nominalization of activities, implying a more direct involvement of the self in the activity.

Based on the excerpts above, we would conclude that the jockey finds more meaning in his actions than does the steel worker or the prostitute. We of course recognize that such a conclusion is far from systematic; however, this brief discussion of the excerpts should make clear how grammatical clues would provide the basis for a more systematic comparison.

\section{Grammatical indicators of meaning}

With these illustrations in mind, we turn now to a discussion of some of the grammatical distinctions uncovered by linguists that can provide clues to the way in which organizational experiences have meaning for those involved. We have defined meaningful action as involving two components: action that is directed toward a broader ideal and action that is pursued in relationship with other members of a community. Operationally, the first component can be measured in terms of the distance of self from action. To the extent that actions are experienced as something external, impersonal or beyond one's control, the possibility for meaning is diminished. The second component can be measured in terms of distance of self from others. To the extent that action is experienced as an individual, rather than collectively shared experience, the possibility for meaning is diminished. 
Work by Halliday and his collaborators (Halliday, 1994; Halliday and Matthiessen, 1999) provides a basis for making inferences about the first component. Halliday treats the clause as the fundamental unit of meaning. It is the linguistic unit by which we impose order and pattern on the otherwise undifferentiated flow of experience. At the level of the clause, experience is construed through "processes" - verbal configurations that can be distinguished on the basis of the grammar. Each clause consists of the process itself, phenomena that play the role of participants in the process, and other phenomena that make up the circumstances of the process (Halliday and Matthiessen, 1999: 512). For example, in the clause, "The boy hit the ball over the fence," we have a process ("hit"), two participants ("the boy" and "the ball”), and a set of circumstantial conditions ("over the fence").

The three main types of process that Halliday identifies correspond to three distinct modes of construing experience. ${ }^{8}$ Material processes are those of doing (to), happening, and creating. These processes take place in the external world (e.g., "I am building a new house”), although material processes can also involve metaphorical doings (e.g., “The manager dissolved the committee”). Mental processes are inner processes of sensing. Thinking, feeling, and seeing are the major subtypes. For example, the clause, "She enjoys her job” would be classified as a mental process, as would the clause, "I feel overwhelmed in my current role.” Finally, relational processes involve classification and identification. They relate one component of experience to another in terms of identity, attributes, or circumstances, as in the clause, "The company has 500 employees.”

\footnotetext{
${ }^{8}$ There are also three hybrid process types; these are elaborated in Halliday, 1994: 106-175.
} 
Importantly, it is features of the grammar that distinguish one type of process from another. For example, in distinguishing material from mental processes, Halliday notes that the unmarked (usual) form of the present tense for material processes is the present-in-present (e.g., "I am building” not "I build”), while the unmarked present tense for mental processes is the simple present (e.g., "I like” not "I am liking”). Moreover, one participant in a mental process must be a conscious being (or an inanimate object endowed with consciousness), while this is not a requirement for material processes. (E.g., The material clause, "The box fell off the shelf," has no conscious participant in it, but you would not say, "The box felt sad," unless you were attributing consciousness to the box.) Our point here is not to elaborate the full set of grammatical rules for distinguishing one type of process from another (the details can be found in Halliday, 1994: 106-175) but simply to point out that the basis for the distinction lies in the grammatical structures at the clause level.

How can the process types be used to identify the extent to which one is distancing oneself from one's actions? Relational processes, in which abstract relations are set up between experiences, can be understood as implying greater distance of self from experience than either material or mental processes. When we choose (consciously or not) to employ a relational construction to describe a particular experience, we are construing this experience in abstract, symbolic terms - classifying it, identifying it as belonging to a particular type, ascribing attributes to it, or specifying its circumstances but we are not directly engaging in the experience itself. The count of relational clauses as a percentage of total clauses in narratives describing one's experience can therefore be 
taken as an indicator of distancing of self from action. The greater the count of relational clauses as a percentage of total clauses, the greater the distancing of self from action.

However, the simple prevalence of material and mental processes over relational processes does not in itself imply that the experience described in a narrative is meaningful. There is an important distinction to be made between material and mental processes. Although the distance between self and action and between self and others may be similar for mental and material processes, the use of mental processes suggests a different type of engagement with the experience - one that is cognitive or emotional in nature. The requirement that at least one participant in a mental process be a conscious being is one indicator of this difference. When we construe experience through a material process, we are making sense of it as an activity in which we may be involved as a participant, but when we construe the experience through a mental process, we are engaging with it on a deeper level. The percent of mental clauses in a narrative is therefore an important second indicator of the extent to which the speaker or writer is deriving meaning from the experience.

Another feature of the grammar of clauses that is particularly useful to us is what Halliday terms "grammatical metaphor." When we think of metaphorical language, we tend to think of what linguists would term "lexical metaphor" - a figure of speech in which a word or phrase that literally denotes one thing is used in place of another, to suggest a similarity between the two. For example, "applauded loudly" could be expressed with the lexical metaphor "applauded thunderously." Grammatical metaphor involves a shift in the grammar rather than the lexis. For example, "applauded loudly" could be expressed with the grammatical metaphor "loud applause.” The grammatical 
metaphor in this case involves a verbal process (“applauded loudly”) being re-construed as a nominal group ("loud applause”). Nominalization of a verbal group is in fact one of the most prevalent forms of grammatical metaphor, although Halliday elaborates a number of others (see Halliday and Matthiessen, 1999: 246-248). The common feature across all types is the shift from one grammatical role to another.

The significance of grammatical metaphor for accessing meaning comes from the fact that the primary tendency in grammatical metaphor is what Halliday describes as "the drift towards 'thing'” - towards expressing circumstances, processes, and qualities as nominal groups (Halliday and Matthiessen, 1999: 263). Nominal groups have the greatest potential for classification and elaboration, and the use of grammatical metaphor therefore tends to expand the options available for conveying information. But it also means that experience becomes construed as more abstract and remote. Instead of construing experience directly, as a process, the speaker or writer construes it remotely, as a piece of information. In this sense, the use of grammatical metaphor implies a depersonalization of experience and greater distance of one’s self from one’s actions. One cannot be a participant in a process once that process has been nominalized. (Although of course the object itself can become a participant in other processes; herein lies the source of the nominal group's potential for elaboration and classification.)

As Halliday acknowledges, "unpacking” a grammatical metaphor into its congruent (non-metaphorical) form can be difficult, as there are often multiple possible congruent forms from which the metaphorical expression could have evolved. However, for our purposes, it is necessary only to recognize the instance of grammatical metaphor, not to unpack it to the precise congruent form intended by the speaker. To assess 
distance from experience, then, one can simply code nominal groups as either grammatical metaphors or congruent forms, and take the percentage of grammatical metaphor as an indicator of the distance of self from action.

The grammatical rules discussed so far have primarily emphasized the first component of meaning - the distance of one's self from one's actions. Analyzing the use of pronouns, as we did in the vignettes, provides some more indication of the first component of meaning, but even more importantly, it provides a means of getting at the second component of meaning - the distance of one's self from others. As noted above, psychologists are increasingly finding the relative prevalence of different pronouns to be indicators of mental states. While we draw on these findings, because our interest is in meaning in the context of organizational work, it would be important to also code whether use of a particular pronoun is embedded in a clause related to work.

[Insert figure 1 here]

Consider some of the implications that could be drawn from coding the degree to which an individual disproportionately relies on the first person singular, first person plural, and third person plural when prompted to discuss work. Figure 1 depicts some possible combinations of pronoun use, where a letter signifies a comparatively heavy use of the pronoun-context combination in the particular cell. For example, A denotes a disproportionate use of first person singular ("I," “me”) for non-work-related clauses and a disproportionate use of third person plural (“they,” "them”) for work-related clauses. This combination clearly suggests that the "self" is not identified with work or with coworkers. In contrast, the combination represented by B - a disproportionate use of the first person singular and first person plural in the work context - does indicate that the 
self is identified with both work and co-workers. The C combination would be expected from an individual who identifies with a natural community, but one that is not centered on work. The D combination denotes an individual who identifies with the people at work, but does not identify his or her self with the activities of work. One might expect this combination from an individual who is part of an organizational subgroup that does not value that company's collective goals. There are clearly other combinations; our purpose here is not to thoroughly review all possible combinations, only to show how the reliance on particles can be used as a basis for making inferences about the meaning that individuals derive from work.

\section{Meaning and "strong" culture}

For readers who may have residual questions or concerns about how our understanding of meaning relates to conceptions of strong culture organizations (e.g., O’Reilly and Chatman, 1996; Deal and Kennedy, 1982), this focus on operationalization should hopefully further clarify the distinction. Proponents of the strong culture concept often emphasize that a strong organizational culture is one in which all individuals espouse similar values (e.g., Kanter, 1983; Peters and Waterman, 1982). However, as work by Van Maanen (1991) and Kunda (1992) illustrates, this espousal may be induced by external constraint or implicit social threat, rather than by individuals' belief in the meaning of their action. In fact, Van Maanen and Kunda's work suggests that a strong culture can undermine the meaning that individuals derive from their actions and also create divisions within the organization, threatening any sense of natural community - for 
example, by imposing uniformity that is actually more aligned with the beliefs of one subgroup in the organization than others.

One might argue that strong culture organizations impose a uniform grammar in addition to a uniform content of beliefs, affecting how people express themselves as much as the content of what people express. Ultimately, this is an empirical question. Arguments about beliefs tend to emphasize the role of stories and rhetoric. Eccles and Nohria (1992), for example, describe the role of organizational rhetoric as sources of worker identity and cognitive categories enabling action. However, there is no work within the strong culture perspective that identifies "grammatical control" as an aspect of strong culture, and even if "grammatical control" were a part of an explicitly managed strong culture, we find it hard to believe that the controls would map onto the indicators of meaningful action that we have identified.

This observation that the grammar of speech is less amenable to strategic manipulation than is the content of speech gives rise to a final point. In emphasizing the importance of grammar as a property of language that provides insight into meaning, we do not wish to imply that content is irrelevant. We certainly expect that one could gain some insight into the consequences of leadership by looking, for example, at counts of positive and negative adjectives, references to an individual's group or organization, and even obvious allusions to meaning or significance. However, we are concerned that, like organizational mission statements that can be posted on a wall but not reflected in individual action, the content of speech is a frequent target of strategic manipulation and impression management. Therefore, at a minimum, we would hope that any focus on content would be complemented by a focus on grammar as a way to minimize the 
confounding effects of personal influence tactics and strategic behavior on the inferences that are drawn from what is said.

\section{Identifying the Scope of Leadership Activities}

Having provided some indication as to how meaningful action might be operationalized, we can now turn to the final issue relevant to answering the second question: how does one assess the extent to which a leader infuses action with meaning? This final issue involves defining the scope of activities with the potential to impact the meaning that individuals experience as part of an organization, and, within this, identifying those that can be effectively labeled as leadership activities. As Bresnen (1995) observes, the scope question is a vexing one for the leadership literature. On the one hand, there has been a tendency to identify leadership with any personality characteristics, behaviors, or actions that can significantly impact on performance. Such an approach suffers from a naïve functionalism and gives rise to the view that leadership is nothing other than an attribution that is made when an organization experiences high performance. On the other hand, there are scholars (e.g., Bass, 1985; Bennis and Nanus, 1985; Rafferty and Griffin, 2004) who have sought to segment out those executive activities that can be labeled "transformational" rather than "transactional," where the former label refers to those activities that change beliefs and values and the latter refers to those activities that change behavior through either positive or negative inducements. The focus on transformational activities has, in turn, led scholars to follow the strong emphasis that Barnard (1968) placed on the communication acts of organizational leaders, reserving other decisions or choices for the label of “management.” However, as 
Bresnen (1995) observes, scholars seem to have given communication acts a privileged status without any actual empirical backing that communication deserves this privileged status. Unless there is some empirical basis for establishing that communication is the most effective leadership tool, such a focus seems unjustifiably restricted.

In our view, this dilemma is a consequence of the trend in the literature that formed the point of departure for this chapter: the insistence that leadership behavior in economic organizations be tantamount to behavior that improves economic performance. Because of this coupling, the distinction between leadership behaviors and characteristics and management behaviors and characteristics becomes either blurred or arbitrary.

However, in so far as leadership is identified with meaning creation, one can then attach the label of leadership to those attributes or behaviors that provide meaning for another as long as those attributes or behaviors can be ascribed to an individual. What do we mean by attributes or behaviors "ascribed to an individual"? We use the phrase to refer to attributes or behaviors where an individual can be identified by the researcher as the agent behind those attributes or behaviors. Agency is, in effect, the inverse of Meyer and Rowan’s (1977) notion of "taken-for-grantedness."” If an individual is seen as undertaking an action or cultivating an attribute that is not taken-for-granted, then the individual can be understood as the agent of that attribute or action. To the degree that the researcher can identify the individual as the agent or author of a particular action and to the degree that the action - either by itself or in combination with other actions on the

\footnotetext{
${ }^{9}$ Given their analytical focus, Meyer and Rowan and those who have followed the neo-institutional tradition have generally conceived of "taken-for-grantedness" at the level of an institutional field. So, when a neo-institutional scholar writes about a taken-for-granted organizational form or taken-for-granted practice, she is usually assuming that the taken-for-granted status is common across the institutional field. For our purposes, the level of analysis that is most relevant is that which encompasses an individual actor and those whom the actor is trying to direct toward a particular goal. In this case, what is taken-for-granted may vary across organizations.
} 
part of the individual - creates meaning for others, the action could be characterized as an act of leadership.

In adopting the perspective of the researcher for the purpose of distinguishing agentic from taken-for-granted acts, we allow for the possibility that organizational members will not always be aware of actions that an individual undertakes to create meaning, and therefore also allow for the possibility that acts of leadership may not always be seen as such by organizational followers. The researcher, of course, confronts an empirical challenge in trying to define the scope of investigation for determining what is taken-for-granted and what is agentic, and in devising a method for objectively attributing an action to an individual. What is not taken-for-granted in a particular organization (e.g., casual dress on Friday) may be taken-for-granted in the broader context in which the organization finds itself, and it is incumbent upon the researcher to make this distinction. However, such empirical challenges seem essentially similar to those faced by institutional theorists and ecologists in adequately defining what is takenfor-granted.

An empirical agenda is thus opened up, in which everything from an individual's choice about task design to her communication acts are examined as potential determinants of the meaning that others derive from what they do. To be clear, we believe it is important to avoid the trap of leadership being an aggregate construct that can encompass all aspects of an executive's behavior - a trap to which we alluded at the outset of this chapter. Impact on meaning must be recognized as a scope-delimiting factor, separating out what is leadership from what is not. As this empirical agenda is followed up, certain actions may in fact acquire a privileged status as a more important 
determinant of meaning. But at the outset, we see no basis on which to privilege some actions over others. In particular, we suspect that an individual may have to engage in significant "transactional" behavior to order institutional conflict (one of the four categories of activity that Selznick (1984) identified with the leadership function), but if the ultimate outcome of that transactional behavior is the creation of a more natural community, then there is no reason that this transactional behavior should be seen as less germane to leadership. ${ }^{10}$

If a researcher were to privilege communication activities to a degree that implied the downplaying of organizational design as an aspect of leadership, the researcher would run the risk of overlooking how the features of the organization would impact on the way the communication is received. For example, the higher the pay disparity within an organization, the more difficult it will be for an individual to infuse meaning with a message of solidarity. The medium is very much a part of the message, and the organization is the medium.

[Insert figure 2 here]

We offer the typology in figure 2 as a way of clarifying our particular specification of attributes, acts, and behaviors with at least the potential to infuse meaning. To the extent that an executive's attributes or behaviors are taken-for-granted (as we have defined the term in this chapter), they are not the attributes, acts, or behaviors of leadership, regardless of their impact on meaning. Rather, it is those attributes, acts,

\footnotetext{
${ }^{10}$ In defining leadership activities in this way, we also treat as an empirical question the relationship between leadership and formal position. Leadership activities are not necessarily performed only by an organization's formal head or senior team. We suspect, of course, that those individuals with greater formal authority will have more opportunities than other organizational members to engage in activities that have the potential to create meaning for a significant number of organizational participants.

Conceptually, however, leadership is not restricted to the occupants of particular formal positions.
} 
and behaviors in the second column of the figure that are the potential "pool" from which leadership attributes, acts, and behaviors are drawn. Exactly which attributes, acts, and behaviors from the second column are most critical for meaning-making is, of course, an empirical question.

To summarize, our answer to the question of how one assesses the extent to which a leader infuses action with meaning has three parts. First, we offer a two-component definition of meaning, where one component refers to the tight connection between one's actions and one's ideals and the other component refers to a feeling of closeness to a natural community. We then argue that linguistic earmarks provide a way of rigorously operationalizing this definition. Finally, given the definition and operationalization of meaning and given the classical identification of leadership with meaning creation, we propose an empirical agenda in which researchers consider a broad range of actions that can impact meaning.

\section{The Relationship between Meaning-Making and Economic Performance}

We have now made clear our position that many of the problems that have confounded the study of leadership can be addressed if a focus on leadership is decoupled from a focus on economic performance and instead coupled to a focus on meaningmaking. However, because so much of the leadership literature currently focuses on the link between leadership and performance, this raises the third question articulated at the outset of the chapter: what is the connection between meaning-making capacity and economic performance? 
We would like to offers two answer to this question. Our first answer is an admittedly defiant one: we don't much care what the relationship is. One of the most significant problems with the study of organizations is that the concern with economic outcomes has trumped the concern with other outcomes. Satisfaction, meaning, social welfare all seem to be regarded as of secondary or mediating significance when compared to economic outcomes such as profitability or survival. In our earlier review of some of the classic scholarship on leadership, we noted that Weber's focus on leadership is at least partially attributable to his concern about the loss of meaning associated with modernity. This concern does not disappear with Weber or other theorists writing at the turn of the century. In The Organization Man, Whyte (1956) voices his concern that the modern corporation does not allow individuals to realize their own unique identity. In The Asymmetric Society, Coleman (1982) observes that “corporate persons” have as many legal rights as “natural persons,” but corporate persons have more resources.

We agree with Selznick’s observation that an obsession with the question of efficiency necessarily detracts from a focus on what is most important. As Selznick asks rhetorically, "Does a preoccupuation with administrative efficiency lead us to the knottiest and most significant problems of leadership in large organizations?” (1984: 2). The meaningfulness of action is an important enough outcome that one should not have to justify a focus on meaning by establishing a connection to economic performance.

Having offered this first answer, we know that it will be dissatisfying to many. Most obviously, it will be dissatisfying to those for whom the relationship between leadership and performance is of central significance. But even if one believes that meaning is the outcome of paramount interest, there are reasons why this first answer 
may not be satisfactory. A leader cannot continue to infuse meaning over time unless the organization can survive, and since survival depends on some minimum level of performance, a focus on meaning cannot be maintained to the complete exclusion of a focus on performance.

Our second answer to this question is therefore the following: there is some work that suggests a positive relationship between the meaningfulness of work and economic performance. For example, Hackman and Oldham's (1980) job characteristics theory specifies that on average, people are more productive when they have a high degree of autonomy and can observe the consequences of their actions. Hackman and Oldham (1980) also find that autonomy and an ability to observe consequences are both positively related to the meaning that individuals derive from work, though they operationalize meaning with responses to direct questions about the meaningfulness of work and not with an operationalization like the one we have suggested above. Moreover, popular management texts (e.g., Collins and Porras, 1994) certainly leave the impression that the long-term prosperity of an organization is enhanced to the degree that the organization has a mission that is regarded as meaningful by the organization's members. However, we would like to see more compelling ways of assessing meaning before drawing definitive conclusions about the impact of meaning and economic performance.

Finally, as scholars explore the relationship between meaning and performance, they should not assume that causality flows entirely from the former to the latter. Just as it seems reasonable to assume that individuals could perform at a higher level when they derive more meaning from their work, so it seems reasonable to believe that a high level of economic performance could positively impact on the meaning that individuals derive 
from their work. As Barnard observed, profitability does not define an organization's purpose; rather, it is an indicator of how well an organization is achieving its purpose (Barnard 1968: 154, especially footnote 7). To the extent that a leader infuses meaning by enabling individuals to realize their ideals and values through organizational action, there will be comparatively little meaning that individuals can derive from association with a poorly performing organization. Put simply, if performing poorly is not much better than not performing at all, one would expect that the level of performance will place an upper bound on the meaning that can be created within an economic organization.

\section{Conclusion}

In this chapter, we have argued that leadership research went awry when the concept of leadership became decoupled from the notion of meaning and inextricably tied to a concern with performance. We considered some explanations for why this decoupling took place; there are several, but probably the most important is the lack of clear definition and operationalization of the meaning that individuals derive from work. Through some illustrations and through guidelines derived from the field of linguistics, we have provided some indications as to how the concept of meaning might be made analytically tractable. Finally, while we argued that a concern with meaning should not always be subordinated to a concern with economic outcomes, we acknowledged that it is important to understand the connection, especially given that the causality can flow in both directions.

[Insert figure 3 here] 
By way of concluding, we would like to reference figure 3, which is intended to further clarify the view of leadership that we have put forth in this chapter. As we did in figure 2, we divide the attributes, acts, and behaviors of an executive into four categories by drawing on the distinctions of transactional versus transformational and agentic versus taken-for-granted. When we conceptualize leadership as meaning-making, we focus on how the attributes and actions that would be categorized as agentic impact on meaning (arrows 2 and 4), as well as on the connection between meaning and performance (arrows 9 and 10). We reserve the term management for all of those executive attributes, acts, and behaviors that impact on performance without creating meaning (arrows 5, 6, 7, and 8). In contrast, the transformational view of leadership tends to emphasize those attributes and actions that would be reflected in arrows 1,2, 5, 6, and 9 - there is no distinction made between taken-for-granted and agentic behavior, and meaning is a relevant outcome only to the extent that it is linked to performance.

This framing creates the possibility for further research to form falsifiable tests of the different conceptions of leadership and the relative importance of leadership and management to economic performance. In terms of figure 3, this would involve testing the magnitude of the different arrows. For example, the strength of arrows 7 and 8 provides some indication of the importance of management as compared to leadership (defined either as transformational leadership or as meaning-making). The strength of the arrows leading to economic performance (arrows 5, 6, 7, and 8), as compared to those leading to meaning (arrows 1, 2, 3, and 4), would provide a test of our argument that meaning be considered as a key outcome. Finally, comparing the magnitude of arrows 1, 
5, and 6 with that of arrows 4 and 10 would provide a test of the transformational concept of leadership as compared to our conception of leadership as meaning-making.

Figure 3 also suggests some related empirical questions. Separate from the relationship between leadership and management on the one hand and meaning and economic performance on the other, considering the relationship between taken-forgranted versus agentic behaviors and transformational versus transactional behaviors leads to a number of interesting research questions. For example, given that the process of institutionalization can be understood as a shift in actions and attributes from agentic to taken-for-granted status, one could be interested in the organizational dynamics underlying this shift. Does it also involve a shift in the nature of executive attributes and actions, from transformational to transactional? One could also be interested in the conditions under which action shifts from taken-for-granted to agentic. To what extent is this shift driven by environmental changes, for example, and to what extent is it driven by changes in individual actors within the organization (e.g., CEO and top management team turnover)?

Clearly there are still some thorny empirical issues that must be addressed before we can investigate such questions, but the empirical challenges should not mask the significance of the broader questions we have raised in this chapter. In asking whether leadership has an impact on performance that transcends the impact of management, we are essentially considering the extent to which agency has more impact when meaning creation is a central target of that agency. Even if we ultimately find that meaning creation does not have a significant impact on economic performance, we maintain that greater attention must be given to meaning as an outcome that is worthy of explanation. 
Meaning creation is an important phenomenon regardless of its relation to economic performance. Indeed, we can think of no other phenomenon that is more worthy of explanation. 


\section{References}

Bales, Robert F. 1950. Interaction Process Analysis: A Method for the Study of Small Groups. Chicago: University of Chicago Press.

Bales, Robert F. and Philip E. Slater. 1955. "Role Differentiation in Small DecisionMaking Groups.” Pp. 259-306 in Talcott Parsons and Philip E. Slater (eds.), The Family, Socialization, and Interaction Processes. Glencoe, Ill.: The Free Press.

Barnard, Chester. 1968. The Functions of the Executive. Cambridge: Harvard University Press.

Bass, Bernard M. 1985. Leadership and Performance Beyond Expectations. New York: The Free Press.

Bell, Daniel. 1976. The Cultural Contradictions of Capitalism. New York: Basic Books.

Bennis, Warren G. 1959. "Leadership Theory and Administrative Behavior: The Problem of Authority.” Administrative Science Quarterly, 4, 259-301.

Bennis, Warren G. and Burt Nanus. 1985. Leaders: Strategies for Taking Charge. New York: Harper \& Row.

Bresnen, Michael J. 1995. “All things to all people? Perceptions, Attributions, and Constructions of Leadership.” Leadership Quarterly, 6(4), 495-513.

Brint, Steven and Jerome Karabel. 1991. "Institutional Origins and Transformations: The Case of American Community Colleges.” Pp. 337-360 in Walter W. Powell and Paul J. DiMaggio (eds.), The New Institutionalism in Organizational Analysis. Chicago: University of Chicago Press.

Brinton, Mary C. and Victor Nee, eds. 1998. The New Institutionalism in Sociology. New York: Russell Sage Foundation.

Calder, Bobby J. 1977. “An Attribution Theory of Leadership.” Pp. 179-204 in Barry M. Staw and Gerald R. Salancik (eds.), New Directions in Organizational Behavior. Chicago: St. Claire.

Campbell, Sherlock R. and James W. Pennebaker. 2003. "The Secret Life of Pronouns: Flexibility in Writing Style and Physical Health.” Psychological Science, 14(1), 60-65.

Carroll, Glenn R. and Michael T. Hannan. 2000. The Demography of Corporations and Industries. Princeton, N.J.: Princeton University Press. 
Clark, Burton R. 1960a. “The 'Cooling-Out Function' in Higher Education.” American Journal of Sociology, 65, 569-576.

Clark, Burton R. 1960b. The Open-Door College: A Case Study. New York: McGraw Hill.

Cohen, Michael D. and James G. March. 1974. Leadership and Ambiguity: The American College President. New York: McGraw Hill.

Coleman, James S. 1982. The Asymmetric Society. Syracuse, N.Y.: Syracuse University Press.

Coleman, James S. 1990. Foundations of Social Theory. Cambridge: Harvard University Press.

Collins, James C. and Jerry I. Porras. 1994. Built to Last: Successful Habits of Visionary Companies. New York: Harper Business.

Deal, Terrence E. and Allan A. Kennedy. 1982. Corporate Cultures: The Rites and Rituals of Corporate Life. Reading, Mass.: Addison Wesley.

DiMaggio, Paul J. and Walter W. Powell. 1983. "The Iron Cage Revisited: Institutional Isomorphism and Collective Rationality in Organizational Fields.” American Sociological Review, 48, 147-160.

Dobbin, Frank and John R. Sutton. 1998. "The Strength of a Weak State: The Rights Revolution and the Rise of Human Resources Management Divisions." American Journal of Sociology, 104, 441-475.

Durkheim, Emile. 1947a. The Division of Labor in Society, translated by George Simpson. Glencoe, Ill.: The Free Press.

Durkheim, Emile. 1947b. The Elementary Forms of the Religious Life: A Study in Religious Sociology, translated by Joseph W. Swain. Glencoe, Ill.: The Free Press.

Durkheim, Emile. 1951. Suicide: A Study in Sociology, edited by George Simpson. Glencoe, Ill.: The Free Press.

Eccles, Robert G. and Nitin Nohria. 1992. Beyond the Hype: Rediscovering the Essence of Management. Boston: Harvard Business School Press.

Emrich, Cynthia G. 1999. “Context Effects in Leadership Perception.” Personality and Social Psychology Bulletin, 25(8), 991-1006. 
Flynn, Francis J. and Barry M. Staw. 2004. "Lend Me Your Wallets: The Effect of Charismatic Leadership on External Support for an Organization.” Strategic Management Journal, 25, 309-330.

Hackman, J. Richard and Greg R. Oldham 1980. Work Redesign. Reading, Mass.: Addison Wesley.

Hackman, J. Richard. 2002. Leading Teams: Setting the Stage for Great Performances. Boston: Harvard Business School Press.

Halliday, M.A.K. 1994. An Introduction to Functional Grammar (2 ${ }^{\text {nd }}$ edition). London: E. Arnold.

Halliday, M.A.K. and Christian M.I.M. Matthiessen. 1999. Construing Experience Through Meaning: A Language-Based Approach to Cognition. New York: Continuum.

Hambrick, Donald and Sidney Finkelstein. 1987. “Managerial Discretion,” Pp. 369-406 in Larry L. Cummings and Barry M. Staw (eds.), Research in Organizational Behavior, 9. Greenwich, CT: JAI Press.

Hannan, Michael T. and John Freeman. 1989. Organizational Ecology. Cambridge: Harvard University Press.

Healy, Kieran. 2004. "Sacred Markets and Secular Ritual in the Organ Transplant Industry.” Pp. 308-331 in Frank Dobbin (ed.), The Sociology of the Economy. New York: Russell Sage Foundation Press.

Hegel, Georg W. F. 1952. The Philosophy of Right, translated by T.M. Knox. New York: Oxford University Press.

Homans, George C. 1950. The Human Group. New York: Harcourt Brace.

House, Robert J., William D. Spangler, and James Woycke. 1991. “Personality and Charisma in the U.S. Presidency: A Psychological Theory of Leader Effectiveness.” Administrative Science Quarterly, 36(3), 364-396.

Kalev, Alexandra, Frank Dobbin, and Erin Kelly. 2004. “Two to Tango: Affirmative Action, Diversity Programs and Women and African-Americans in Management.” Harvard University: Working Paper.

Kanter, Rosabeth Moss. 1983. The Change Masters. New York: Simon and Schuster.

Kelly, Erin and Frank Dobbin. 1998. "How Affirmative Action Became Diversity Management.” American Behavioral Scientist, 41, 960-984. 
Kerr, Stephen and John M. Jermier. 1978. "Substitutes for Leadership: Their Meaning and Measurement.” Organizational Behavior and Human Performance, 22, 375403.

Khurana, Rakesh. 2002. Searching for a Corporate Savior: The Irrational Quest for Charismatic CEOs. Princeton, N.J.: Princeton University Press.

Kotter, John P. 1988. The Leadership Factor. New York: The Free Press.

Kunda, Gideon. 1992. Engineering Culture: Control and Commitment in a High-Tech Corporation. Philadelphia: Temple University Press.

Lieberson, Stanley and James F. O’Connor. 1972. “Leadership and Organizational Performance: A Study of Large Corporations.” American Sociological Review, 37, 117-130.

Marchand, Roland. 1998. Creating the Corporate Soul: The Rise of Public Relations and Corporate Imagery in American Big Business. Berkeley, Calif.: University of California Press.

Martin, Joanne. 1992. Cultures in Organizations: Three Perspectives. New York: Oxford University Press.

Matthiessen, Christian M.I.M. and M.A.K. Halliday. 1997. "Systemic Functional Grammar: A First Step into the Theory.” Macquarie University, Australia: Working Paper.

Mayo, Elton. 1960. The Human Problems of an Industrial Civilization. New York: Viking Press.

Meindl, James R., Sanford B. Ehrlich, and Janet M. Dukerich. 1985. “The Romance of Leadership.” Administrative Science Quarterly, 30, 78-102.

Meyer, John W. and Brian Rowan. 1977. "Institutionalized Organizations: Formal Structure as Myth and Ceremony.” American Journal of Sociology, 83, 340-363.

O’Reilly, Charles A. III and Jennifer A. Chatman. 1996. "Culture as social control: Corporations, Cults, and Commitment.” Pp. 157-200 in Barry M. Staw and Larry L. Cummings (eds.), Research in Organizational Behavior, 18. Greenwich, Conn.: JAI Press.

Pennebaker, James W. 2002. "What Our Words Can Say About Us: Toward a Broader Language Psychology.” Psychological Science Agenda, 15, 8-9. 
Pennebaker, James W. and Anna Graybeal. 2001. "Patterns of Natural Language Use: Disclosure, Personality, and Social Integration.” Current Directions in Psychological Science, 10, 90-93.

Peters, Thomas J. and Robert H. Waterman. 1982. In Search of Excellence. New York: Harper and Row.

Pfeffer, Jeffrey and Christina T. Fong. Forthcoming. “The Business School 'Business': Some Lessons from the U.S. Experience.” Journal of Management Studies.

Pfeffer, Jeffrey and Gerald R. Salancik. 1978. The External Control of Organizations. New York: Harper and Row.

Pfeffer, Jeffrey. 1977. “The Ambiguity of Leadership.” Academy of Management Review, 2(1), 104-112.

Pfeffer, Jeffrey. 1981. "Management as Symbolic Action: The Creation and Maintenance of Organizational Paradigms.” Pp. 1-52 in Barry M. Staw and Larry L. Cummings (eds.), Research in Organizational Behavior, 3. Greenwich, Conn.: JAI Press.

Pfeffer, Jeffrey. 1987. “A Resource Dependence Perspective on Intercorporate Relations.” Pp. 25-55 in M.S. Mizruchi and M. Schwartz (eds.), Intercorporate Relations: The Structural Analysis of Business. Cambridge: Cambridge University Press.

Pfeffer, Jeffrey. 1997. New Directions for Organization Theory: Problems and Prospects. New York: Oxford University Press.

Pfeffer, Jeffrey and Allison Davis-Blake. 1986. “Administrative Succession and Organizational Performance: How Administrator Experience Mediates the Succession Effect.” Academy of Management Journal, 29, 72-83.

Powell, Walter W. and Paul J. DiMaggio, eds. 1991. The New Institutionalism in Organizational Analysis. Chicago: University of Chicago Press.

Rafferty, Alannah E. and Mark A. Griffin. 2004. "Dimensions of Transformational Leadership: Conceptual and Empirical Extensions.” Leadership Quarterly, 15, 329-354.

Roethlisberger, Fritz J., and William J. Dixon. 1939. Management and the Worker. Cambridge: Harvard University Press.

Rousseau, Jean-Jacques. 1993. The Social Contract and Discourses, translated by G.D.H. Cole. London: Everyman. 
Roy, William G. 1997. Socializing Capital: The Rise of the Large Industrial Corporation in America. Princeton, N.J.: Princeton University Press.

Salancik, Gerald R., and Jeffrey Pfeffer. 1978. "A Social Information Processing Approach to Job Attitudes and Task Design.” Administrative Science Quarterly, 23, 224-253.

Selznick, Philip. 1952. The Organizational Weapon: A Study of Bolshevik Strategy and Tactics. Santa Monica, Calif.: The Rand Corporation.

Selznick, Philip. 1984. Leadership in Administration: A Sociological Interpretation. Berkeley, Calif.: University of California Press.

Shils, Edward. 1982. The Constitution of Society. Chicago: University of Chicago Press.

Silverstein, Michael. 2003. "Indexical Order and the Dialectics of Sociolinguistic Life.” Language and Communication, 23, 193-229.

Smelser, Neil J. 1995. “Economic Rationality as a Religious System.” Pp. 73-92 in Robert Wuthnow (ed.), Rethinking Materialism: Perspectives on the Spiritual Dimension of Economic Behavior. Grand Rapids, Mich.: William B. Erdmans.

Sørensen, Aage B. 1998. "Theoretical Mechanisms and the Empirical Study of Social Processes.” Pp. 238-266 in Peter Hedström and Richard Swedberg (eds.), Social Mechanisms: An Analytical Approach to Social Theory. New York: Cambridge University Press.

Stogdill, Ralph M. 1974. Handbook of Leadership: A Survey of Theory and Practice. New York: The Free Press.

Swedberg, Richard. 1998. Max Weber and the Idea of Economic Sociology. Princeton, N.J.: Princeton University Press.

Terkel, Studs. 1972. Working. New York: Random House.

Thomas, Alan Berkeley. 1988. "Does Leadership Make a Difference to Organizational Performance?” Administrative Science Quarterly, 33, 388-400.

Tichy, Noel M. and Mary Anne Devanna. 1986. The Transformational Leader: The Key to Global Competitiveness. New York: Wiley.

Tonnies, Ferdinand. 1957. Community and Society, translated and edited by Charles P. Loomis. East Lansing, Mich.: Michigan State University Press.

Van Maanen, John. 1991. “The Smile Factory: Work at Disneyland.” Pp. 58-76 in P. Frost et al. (eds.), Reframing Organizational Culture. Newbury Park, Calif.: Sage. 
Walsh, James P., Klaus Weber, and Joshua D. Margolis. 2003. "Social Issues and Management: Our Lost Cause Found.” Journal of Management, 29, 859-881.

Wasserman, Noam, Bharat Anand, and Nitin Nohria. 2001. "When Does Leadership Matter? The Contingent Opportunities View of CEO Leadership.” Harvard University Working Paper Series, No. 01-063.

Weber, Max. 1946. From Max Weber: Essays in Sociology, edited by H. H. Gerth and C. Wright Mills. New York: Oxford University Press.

Weber, Max. 1964. The Theory of Social and Economic Organization, edited by Talcott Parsons. New York: The Free Press.

Weber, Max. 1978. Economy and Society, Volume Two, edited by Claus Wittich and Guenther Roth. Berkeley: University of California Press.

Weber, Max. 1992. The Protestant Ethic and the Spirit of Capitalism. New York: Routledge.

Weber, Roberto, Colin Camerer, Yuval Rottenstreich, and Marc Knez. 2001. "The Illusion of Leadership: Misattribution of Cause in Coordination Games." Organization Science, 12(5), 582-598.

Weeks, John. 2004. Unpopular Culture: The Ritual of Complaint in a British Bank. Chicago: University of Chicago Press.

Whyte, William H. 1956. The Organization Man. New York: Simon and Schuster.

Zelizer, Viviana A. 1979. Morals and Markets: The Development of Life Insurance in the United States. New York: Columbia University Press.

Zelizer, Viviana A. 1985. Pricing the Priceless Child: The Changing Social Value of Children. New York: Basic Books. 
Figure 1: Some pronoun profiles

\begin{tabular}{|c|c|c|c|c|c|}
\hline & & $\begin{array}{l}1^{\text {st }} \text { pers } \\
\text { singular }\end{array}$ & $\begin{array}{c}1^{\text {st }} \text { pers } \\
\text { plural }\end{array}$ & $\begin{array}{l}3^{\text {rd }} \text { pers } \\
\text { plural }\end{array}$ & Other \\
\hline \multirow{2}{*}{$\begin{array}{l}\text { Work } \\
\text { clause }\end{array}$} & Yes & $B$ & $B, D$ & $A, C$ & \\
\hline & No & $A, D$ & $C$ & & \\
\hline
\end{tabular}
A self not identified with work or co-workers
$B$ self identified with work and co-workers
C self not identified with co-workers, but with natural community outside of co-workers
D self identified with co-workers, but self is apart from activity of work 
Figure 2: A Typology of Executive Attributes, Acts, and Behaviors

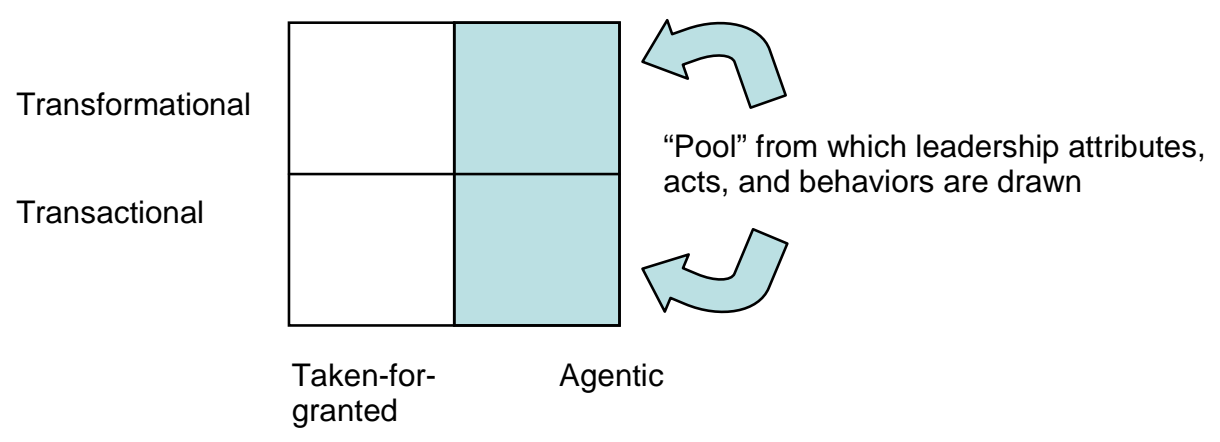


Figure 3: Conceptions of Leadership and Management

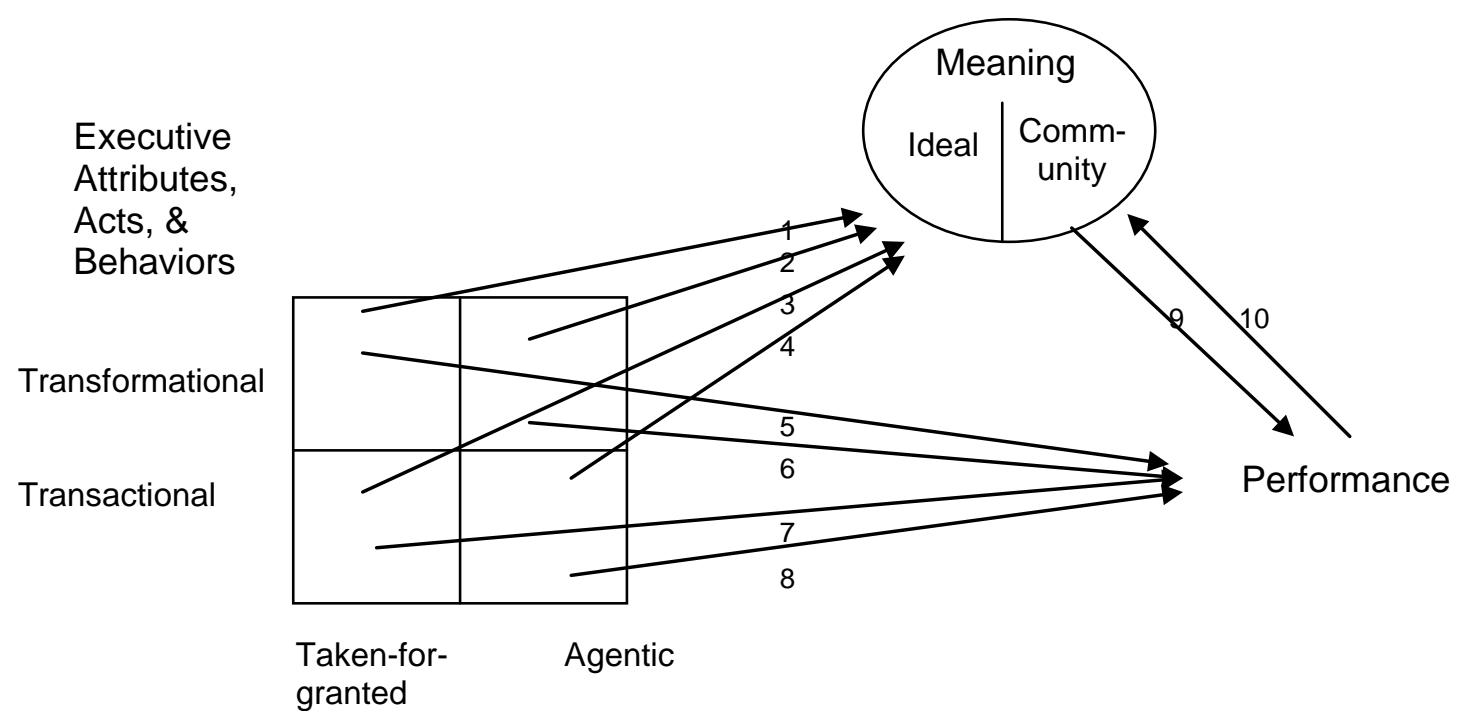

